\title{
Emotion and Group Cohesion in Productive Exchange $^{1}$
}

\author{
Edward J. Lawler \\ Cornell University \\ Shane R. Thye \\ University of South Carolina \\ Jeongkoo Yoon \\ Ajou University
}

\begin{abstract}
This study refines and experimentally tests a theory of relational cohesion that explains how and when actors become committed to one another in the context of multiactor exchange. The theory asserts that frequent social exchange results in (1) positive emotions that solidify and strengthen the person-to-group bond and (2) uncertainty reduction that renders the focal group more salient in relation to others. These two mechanisms produce a sense of psychological group formation and ultimately increase observable acts of commitment. In a "productive exchange" setting, three actors negotiate a joint venture that requires the assent of all members. The exchanges featured two forms of commitment behavior: the giving of small token gifts and the decision to invest in a three-way prisoner's dilemma. The results suggest that positive emotion and uncertainty reduction are theoretically distinct and affect commitment behavior through different mechanisms. The article concludes by discussing the general implications for commitment and social order.
\end{abstract}

\section{INTRODUCTION}

Social exchange is inherently a joint activity in which two or more actors attempt to produce a flow of benefits better than they can achieve alone

\footnotetext{
${ }^{1}$ This research was funded by the National Science Foundation (SBR-95 14860). Earlier versions of this article were presented at the 1998 American Sociological Association meeting in San Francisco and at the 1999 Pacific Sociological Association meetings in Portland. The authors thank Marty Kuhn for his programming skills and Wes Sine for help with the data collection. We thank several AJS reviewers for helpful comments.
}

(C) 2000 by The University of Chicago. All rights reserved.

0002-9602/2000/10603-0003\$02.50 
or in other relationships. The jointness of the task varies across forms or types of social exchange, as does the underlying interdependency among the actors (Thibaut and Kelley 1959; Blau 1964). To the degree that social exchanges recur among the same actors, the properties of jointness and interdependence should promote the development of relationships or groups. One explanation for this is uncertainty reduction (Cook and Emerson 1984; Kollock 1994), another is positive emotion (Lawler and Yoon 1993, 1996, 1998). These two processes are more or less robust across various types of social exchange, and in a larger sense, they are key foundations for solidarity and social order. In this article, we examine a neglected form of social exchange, productive exchange, and test the role of uncertainty reduction and emotional/affective processes in the development of person-to-group commitments. We take person-to-group commitment or attachment as a reflection of emergent group formation (Tajfel and Turner 1979, 1986; Rabbie and Horowitz 1988; Kramer 1993; Parsons 1951).

Productive exchange is based on mutual interdependencies that are strong enough to make joint action or collaboration the most profitable option to individual actors. Examples include neighbors deciding to arrange for the landscaping of a common area, universities agreeing to develop a joint distance-learning program, corporations negotiating their respective contributions to a joint lobbying effort directed at a state legislature, or several unions developing a common approach to negotiations with a city government. In each case, two or more actors can produce a joint good by contributing their individual resources or talents to the collective endeavor. In productive exchange, there are strong incentives for exchange, and the main question is whether the actors can coordinate their actions to forge agreements.

Productive exchange is one of four fundamental forms of social exchange identified by exchange theorists (Emerson 1972, 1981; Molm 1994; Molm and Cook 1995); the other basic forms include negotiated, reciprocal, and generalized exchange. Negotiated exchange involves explicit and binding agreements, about actor-to-actor flows of benefit, made at a single point in time. Reciprocal exchange involves sequences of unilateral giving among two actors over time. The common thread here is that both kinds of exchange are inherently dyadic, that is, each involves "direct" transactions between two actors. Generalized exchange is a unilateral form of exchange in which givers and receivers are not matched in pairs, that is, $\mathrm{A}$ gives to $\mathrm{B}$ who gives to $\mathrm{C}$ who gives to A. Productive

The order of authorship was determined alphabetically and does not reflect differential contributions. Direct correspondence to Edward J. Lawler, School of Industrial and Labor Relations, Cornell University, Ithaca, New York 14853. 


\section{American Journal of Sociology}

exchange is indirect and generalized in the sense that it entails a personto-group and group-to-person exchange. Molm (1994) aptly terms this a "group cooperation" subtype of exchange, while Yamagishi and Cook (1993) describe it as "group generalized exchange." ${ }^{2}$

Productive exchange is the most group-oriented form of exchange (Emerson 1972, 1976, 1981; Yamagishi and Cook 1993; Molm 1994; Molm and Cook 1995). It is also the least studied. Exchange theorists tend to use the term productive exchange in somewhat variable ways (see Emerson 1972; Molm 1994; Molm and Cook 1995), so our first task is to sharpen the concept. We define productive exchange in terms of four properties as follows.

First, productive exchange involves two or more individuals who generate a single, socially produced object or event. The rewards from productive exchange may be divisible (as when three corporations jointly generate a profit) or indivisible (as when three colleagues author a manuscript), but in either case, there is a single source of profit that all share in some way (Emerson 1972, 1981). Of special importance is the relation between the actor and group: the flow of contributions are from person to group, and the flow of rewards are from group to person. Productive exchange can occur in dyads or larger groups, but the prototype of productive exchange involves three or more actors, because in such groups the person-to-group feature is more easily separable from person-to-person attachments. In dyadic productive exchange, the person-to-group bond is more wrapped up with the person-to-person bond.

Second, compared to the other forms of exchange mentioned above, productive exchange involves higher degrees of interdependence, that is, joint control over outcomes (Molm 1994). This is manifest in the fact that (1) the potential profits from a productive exchange are greater than any other option actors have, and (2) successful exchange requires the assent of all group members. Noncooperation by any single individual is sufficient to prevent the exchange from transpiring. ${ }^{3}$ Exchange theorists since

\footnotetext{
${ }^{2}$ In direct exchange (negotiated or reciprocal), each actor provides valued benefits to the other, yet no additional value is produced by their joint acts, A giving to B and $\mathrm{B}$ giving to $\mathrm{A}$. In productive exchange, the combination of these benefits is greater than the sum of the individual benefits, e.g., group benefit $>\mathrm{A}+\mathrm{B}$. If $\mathrm{A}$ and $\mathrm{B}$ are scholars, direct exchanges might involve each providing comments on the other's papers; productive exchange might involve joint work, such as a coauthored paper in which each brings different talents or expertise. Direct exchange produces benefits for each, whereas productive exchange produces a joint good.

${ }^{3}$ It should be noted that free riding is not relevant here. Free riding would be an issue in productive exchange if (1) the good is public and therefore accessible to parties who are not a part of the collaboration, or (2) the parties to the productive-exchange agreement can abrogate the agreement afterward, i.e., not fulfill its terms. In our research, the joint goods are under control of the parties to productive exchange, and the
} 
Thibaut and Kelley (1959) have recognized interdependence as a central property of exchange, and recent theorizing of exchange structures (Molm 1994; Molm and Cook 1995) has identified important structural variations in interdependence that make productive exchange stand out as the most cooperative.

Third, productive exchange occurs in a context that poses significant coordination problems. These make it difficult for actors to realize their mutual interests despite incentives to do so. ${ }^{4}$ The coordination problems can be due to limited communication because of the number of individuals involved, or because of the constraints on the exchange process. For example, in negotiated exchange coordination problems occur if the offers made by multiple partners are simultaneous rather than sequential; whereas in reciprocal exchange long delays between the unilateral benefit flows would generate coordination problems. In this research, we use a multiactor, person-to-group negotiation context to create the necessary coordination problems.

Fourth, in productive exchange, each actor makes a single demand or claim from a single pool of rewards produced at the group level. For example, a corporation may ask for a certain percent of the revenue generated by a four-way consortium or a high school may ask for a certain level of access to a jointly developed practice field. A single pool of groupgenerated resources distinguishes productive exchange from "inclusively" or "positively" connected relations where payoffs stem from multiple pools at the dyadic level (see Patton and Willer 1990; Willer 1999; Emerson 1981). If the product of productive exchange is divisible, as in the above examples, decisions about whether to engage in a collaborative effort also entail decisions about how benefits are to be shared.

It is the combination of the above four properties that give productive exchange its distinctive character. Productive exchange is a grouporiented, coordination task in which actors seek to produce a valued result through their joint collaboration. Productive exchange can involve a negotiated or reciprocal form of person-to-group, group-to-person exchange. For example, three actors could be negotiating the division of profits from a mutual fund, or each could be giving monetary contributions to the group without a specified future return. In the former, where the benefits from productive exchange are negotiated, there is less uncertainty about

exchange agreements are binding. We impose these particular conditions experimentally, but the concept of productive exchange also applies to conditions where free riding is possible.

${ }^{4}$ Theoretically, if coordination problems of some sort did not exist, the mutual interests and incentives favoring exchange would lead actors to reach an accommodation easily. See Schelling (1960) for a related discussion of coordination problems in contexts with strong incentives for cooperation. 


\section{American Journal of Sociology}

the contingencies of reward because agreements are explicit and binding (Molm 1994).

We address two theoretical questions in this research. First, under what conditions will productive exchange among three actors generate a sense of groupness and cohesion among them? Second, what role do emotions and feelings play in this cohesion process, and how does this compare to traditional exchange-theoretic explanations that center on uncertainty reduction? We assert that group cohesion, defined as the perception of the group as a unifying force or object, is an important part of the commitment process. Higher group cohesion should cause members to remain in the group despite valued alternatives, engage in symbolic or token gestures that signify the group border, initiate new ventures involving risk, and avoid exercising power against other group members. Such behaviors indicate actors have formed a person-to-group tie and, through this, have developed a commitment to the group and its members.

Parsons (1951) drew a sharp distinction between person-to-person and person-to-group attachments, arguing that the latter are crucial to social order because individuals are limited in the number of social relations they can or will maintain. Even in relatively small groups, each dyadic relation will not necessarily form or be equally strong. Groups, as such, endure by having common foci, experiences, and identities above and beyond interpersonal ties among actors (Brewer 1993; Collins 1981). The importance of person-to-group ties is further evidenced in the organizational commitment literature (Kanter 1968, 1972; Hall 1988; Lincoln and Kalleberg 1985; Lawler 1992a) and in psychological analyses of social identity (Tajfel and Turner 1986; Hogg and Turner 1985; Rabbie and Horowitz 1988). In social-identity terms, "psychological group formation" is a powerful unifying force among a set of interdependent actors (see also Berger and Luckmann 1967, pp. 57-60; Collins 1989). Applied to the forms of exchange, productive exchange should be especially conducive to person-to-group ties.

Productive exchange is prone to such attachments because, in the abstract, joint social activities generate positive emotions or feelings. We certainly are not the first to recognize this connection. The same point was central to Durkheim's (1915) analysis of ritual behavior as detailed in his Elementary Forms of Religious Life, and has been used extensively by Collins $(1981,1989)$ in his theory of interaction ritual chains. Collins postulates that joint activity produces a common focus, a sense of group affiliation, and an emotional uplift associated with the group interaction. Applied to productive exchange, this common focus should heighten the degree to which reaching agreements will produce an "emotional buzz"-feeling good, elated, energized; whereas failing to reach agreements will produce an "emotional down"-feeling bad, disappointed, de- 
pressed. Lawler and Yoon $(1996,1998)$ have developed and tested a theory of relational cohesion that explicates this process for negotiated exchange among dyads in a network. Now we aim to theorize and test whether productive social exchange among multiple actors promotes cognitive or psychological group formation through comparable emotional processes.

\section{BACKGROUND}

Social exchange theory has focused on contexts where two or more actors seek to arrive at a satisfactory exchange of benefits. It is generally assumed that individuals exchange for instrumental reasons. In the parlance of exchange theory, successful exchange is a rewarding or reinforcing event, while failed exchange is a costly or punishing event. Exchange theory presumes that people exchange repeatedly with the same actors when success occurs but move to others when failure occurs. The underlying theoretical mechanism here may be either operant conditioning (Homans 1961; Emerson 1972) or rational choice (Kollock 1994; Cook and Whitmeyer 1992; Macy 1993).

The standard exchange-theory explanation for commitment is that frequent exchange reduces uncertainty. When actors repeatedly exchange resources, they should learn more about one another, find each other more predictable, and infer that they have similar orientations to the exchange task. Predictability, expectation confirmation, and the like can be considered a benefit of staying with the same actor (Emerson 1981; Molm 1994; Molm and Cook 1995). Research in cognitive psychology supports the notion that individuals tend to avoid unpredictable or uncertain decision contexts (Tversky and Kahneman 1974; Kahneman and Tversky 1979, 1996). More recently, the uncertainty-reduction hypothesis has been affirmed by Kollock (1994) who shows that commitment is more likely to form in spot markets, where the quality of the products bought are unknowable. A simple way to characterize this point of view is shown in figure 1.

This same theme emerges in a variety of other commitment explanations, ranging from those centered on trust (Pruitt and Kimmel 1977; Yamagishi 1995) or relation-specific assets (Williamson 1981) to those dealing with embeddedness within larger social units (Granovetter 1973, 1985). Taken as a whole, these theories generally concur that reduced uncertainty sets focal relations or groups apart from others and increases their instrumental value to actors.

We adopt a somewhat different approach, starting with the premise that commitment in dyads and larger groups may grow from expressive, as well as instrumental, foundations (Parsons 1951). We argue that with 
repetitive exchange, groups and relations become salient social objects that have a cognitive or subjective reality to actors. As such, these relations or groups may take on objective value and become ends in themselves (Berger and Luckmann 1967; Collins 1989; Lawler and Yoon 1996). Within exchange theories, the expressive character of group formation is translated into instrumental language and thus loses independent theoretical status (see Lawler and Thye [1999] for further discussion). Our focus on the expressive underpinnings of commitment extends and complements the traditional social exchange approach based on instrumental behavior.

The instrumental foundation assumed by exchange theorists makes microsocial orders, in the form of social relations and groups, tenuous and unstable. One might imagine social life as a grand spot market in which ties do form, but they have difficulty enduring in the context of competitive bidding, free rider problems, and changing incentives in the environment (Frank 1988, 1993). Microsocial orders-that is, stable networks of relations or groups-are problematic because of the uncertainties and risks involved in forming enduring or lasting social bonds or connections (e.g., Molm 1994; Frank 1988). Several solutions have been proposed for social order problems of this nature, especially in the rational choice and social dilemma literatures (e.g., Hardin 1968; Hechter 1987; Macy 1993; Yamagishi 1995), and exchange theorists have imported many of these ideas into their theorizing about networks (Yamagishi and Cook 1993; Molm 1994; Lawler and Yoon 1996). Because many exchanges occur in the context of environmental uncertainty, the majority of the solutions are directed at conditions that reduce risk and uncertainty (Molm and Cook 1995).

Lawler and Yoon (1996) put forth an alternative explanation for commitment, one based on the emotional/affective processes exchange tends to induce. This approach is based on the notion that success at exchange makes people feel good, while failure makes them feel bad (see Willer, Lovaglia, and Markovsky [1997] for evidence; see Gillmore [1987] for potential qualifications). The "theory of relational cohesion" contends that individually felt emotions unleash a cognitive process through which the emotion is attributed in part to the relations or groups that constitute the context for exchange. In this manner, groups can become objects of intrinsic value to actors due to the positive emotions generated from exchange. As such, the social order problems inherent in uncertain or unpredictable relations are not as problematic. This theoretical argument is captured in figure 2 .

Thus, there are two exchange-theoretic explanations for commitment, an emotional/affective one and an uncertainty reduction one. Uncertainty reduction emphasizes the instrumental side of exchange while the emo- 
tional/affective mechanism stresses the expressive. In the current research, we seek to determine if uncertainty reduction predicts person-to-group commitment in a productive exchange context and to assess if the emotional/affective processes observed previously adds explanatory power. Affirmative answers to these questions would verify two independent mechanisms through which actors become committed to each other in productive exchange. ${ }^{5}$

In addition, this research extends the theory of relational cohesion beyond the dyad by investigating the commitment processes in multiactor (i.e., triadic) exchange. The move from dyads to triads has important theoretical implications for exchange if combined with a productive exchange structure. For instance, in triads, compared to dyads, each actor has to predict and anticipate the behavior of two others instead of one, which makes it even more difficult for actors to coordinate their behaviors. Because there also is more uncertainty about reaching agreement, successful exchanges are likely to be perceived as a more significant accomplishment. Thus, in a multiactor productive exchange context, repeated exchange should have stronger effects on the perceived predictability of the others, and successful transactions should produce even stronger positive emotions. We investigate a three-actor productive exchange because this is the simplest case of multiactor productive exchange wherein personto-group ties are distinct from the interpersonal bonds (Simmel 1950; Berger and Luckmann 1967). ${ }^{6}$

\section{THE THEORY}

The central idea of our theorizing and research is that social exchange has emotional effects on actors, and if these are attributed to social units, the social unit takes on expressive value or intrinsic worth. Persons develop stronger ties to groups that are perceived as a source of positive feeling or emotion and weaker ties to those perceived as a source of negative feelings or emotion. These ties are instrumental to the degree they reflect the benefits of mutually satisfactory exchange; they are expressive to the degree the social unit is an object of affective attachment.

\footnotetext{
${ }^{5}$ One might argue that these two mechanisms are intertwined: a reduction of uncertainty could enhance positive feelings, or positive feelings may generate a greater sense of predictability. Relational cohesion theory assumes these are parallel processes, produced by a common cause, i.e., repetitive exchange, and there is some evidence for this (see Lawler and Yoon 1996). Our measurement procedures and empirical test isolate these mechanisms accordingly.

${ }^{6}$ Simmel (1950) argues that triads are the smallest group in which people begin to perceive the force, presence, or reality of a social unit external to themselves.
} 


\section{American Journal of Sociology}

The theory of relational cohesion shows how emotions generate such affective attachments (Lawler and Yoon 1996, 1998). In this article, by incorporating uncertainty reduction as a distinct pathway to commitment and group formation, we broaden the theory and make it possible to address both instrumental and expressive consequences of repetitive exchange and structural power dependence conditions.

The theory contains three foundational ideas. First, network structures shape who is likely to interact and exchange with whom, by providing incentives for actors to exchange with some and not others (Skvoretz and Lovaglia 1995). The same actors are likely to exchange with each other across time under fixed structural conditions. Second, successful exchange efforts produce an emotional buzz, that is, mild, positive feelings; while failure to accomplish exchange generates mild negative feelings (Lovaglia 1997; Lawler and Yoon 1996, 1998). The emotions of concern here are involuntary internal events that simply "happen to people" (Hochschild 1983). ${ }^{7}$ Third, actors are motivated to understand the sources of these feelings because they want to reproduce good feelings and avoid bad feelings in the future. Yet, the source of these feelings is unclear, given that exchange entails a joint accomplishment. This presents actors with an attribution problem (see Weiner [1985] for a relevant theory). The result is "cognitive work" by individuals, in which social units-exchange relations or groups-are a part of their explanation for the emotions felt. In productive exchange, then, groups become objects of attachment to the degree that they are perceived as a source of positive individual feelings. Cohesion and commitment behavior are consequences of this.

In figure 3, we offer a modified theory of relational cohesion that incorporates the effect of uncertainty. The appendix contains a formalization. The exogenous, endogenous, and dependent variables are discussed in turn below.

The exogenous conditions are the structural relations of power dependence or interdependence among the actors (Emerson 1981; Molm 1994). Power is defined as the structural capability for some actors to extract resources from others as determined by levels of dependence. Power capability is distinct from power use (tactics or strategies) and the actual or realized power manifest in the division of payoffs (Emerson 1972, Bacharach and Lawler 1981; Lawler 1992b; Molm 1987). Adapting Emerson's concept of dependence to a group of multiple actors sharpens the

\footnotetext{
${ }^{7}$ An emotion is defined as a relatively short-lived positive or negative evaluative state that involves neurophysiological, neuromuscular, and sometimes cognitive elements (Kemper 1978; Izard 1977).
} 


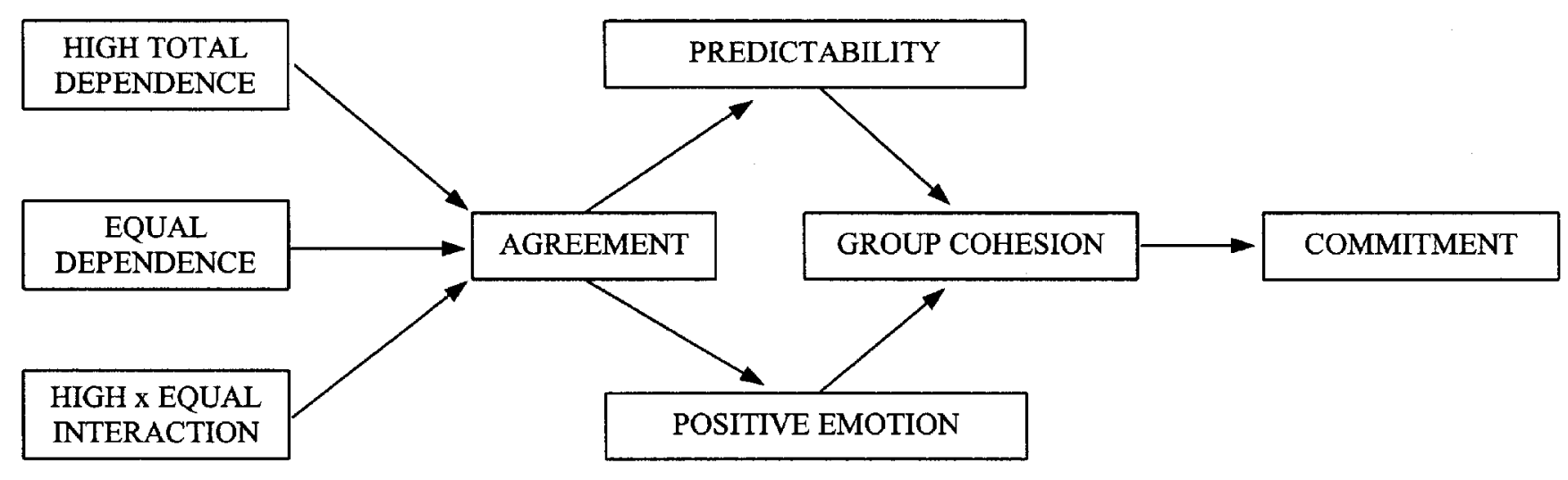

FIG. 3.-The revised theory of relational cohesion 
American Journal of Sociology

distinction between person-to-person and person-to-group dependencies. ${ }^{8}$ Assuming a set of actors in a group, each actor's dependence on the group is equal to the maximum benefit from the focal group versus the maximum benefit from an alternative group. The total or mutual interdependence in the group refers to the average of each members' individual dependence on the group. Dependence equality/inequality refers to the relative differences between members' dependence on the group (see the appendix, below, for formal definitions). In this research, we experimentally cross low versus high total (average) dependence on the group with equal versus unequal dependence on the group.

The theory predicts that greater total dependence and equal versus unequal dependence will produce more frequent exchange in the focal group. Higher total dependence increases the opportunity costs of opting for an alternative group affiliation; it also gives members more flexibility to adapt and more room for misperception or miscalculation. This is because there is a larger range of agreements that meet a "sufficiency" criterion, that is, provide each actor more than the expected value from the alternative group. The negative impact of dependence inequality reflects the fact that inequalities of power will raise issues of fairness and legitimacy that are likely to be absent under equal dependence (Molm 1990; Brines and Joyner 1999). The interaction effect indicates that the combination of high total and equal dependence on the group should produce an extra structural push toward repetitive exchange and the resulting group formation (i.e., commitment) process.

The theory posits an indirect sequence by which structural power dependence conditions promote group formation. In fact, the endogenous process is the heart of the theory. It starts with the exchange frequencies produced by the structure of dependence. One endogenous path operates through the uncertainty reduction effects of exchange frequency, and the second endogenous path operates through the emotional/affective effects of exchange frequency. These two processes converge in that each enhances perceptions that the group is a unifying or cohesive unit (see also Bollen and Hoyle 1990). The theory assumes that these effects are distinct, analytically and empirically. Our prediction is that the two paths represent different, but complementary, explanations for how group formation emerges out of social exchange processes.

\footnotetext{
${ }^{8}$ One of the most important insights of Emerson's power dependence theory is that power dependence relations are nonzero sum. This means that the average or total dependence in a relation can vary independently of the relative or equality/inequality of power. Bacharach and Lawler (1981), Molm (1987), and Lawler and Yoon (1996) have further developed this idea. A nonzero sum concept is particularly important for productive exchange because a key property of this form of exchange is mutual interdependence.
} 
The main dependent variables are commitment behaviors, two forms of which are investigated here: token gifts provided to others unilaterally and without strings or contingencies, and willingness to contribute to a new joint venture. ${ }^{9}$ Token gifts in this research lack instrumental value and are symbolic of a shared group affiliation; the new joint venture takes the form of a $N$-person social dilemma where noncontributing is the dominant strategy and the well-known disparity between individual and collective rationality is present (Platt 1973; Axelrod 1984). Gift giving can be construed as more expressive than contribution behavior, while contribution behavior is more instrumental than gift giving. These behaviors are observed after actors have had the opportunity to establish a sense of group through frequent or repetitive exchange. Previous tests of relational cohesion theory have found the predicted effects on these forms of commitment behavior in a negotiated exchange context (see Lawler and Yoon 1993, 1996; Lawler et al. 1995).

The two endogenous paths can be construed as capturing different facets of group formation. Uncertainty reduction is a boundary-defining process by which actors come to see the group as set off from other relations or groups. This occurs because of the risks associated with less predictable relations and groups. Research in psychology generally indicates that actors avoid risking the loss of highly probable benefits, like those anticipated from predictable exchange (Tversky and Kahneman 1981). This preference should shift the orientation of actors toward more predictable exchange relations, making them a salient object of awareness. In this manner, predictable relations may come to have "distinctiveness" in social identity terms (Brewer 1993) as they are cognitively set off from others.

The emotional effects of exchange can be interpreted as a social bonding process through which the group becomes an object of intrinsic or expressive value. This occurs because actors perceive the group context as partly responsible for their positive feelings, suggesting the "valuation" dimension of group formation that is sometimes referred to as "group status" (Brewer 1993) or "group value" (Tyler 1990, 1994). It is now generally accepted that group distinctiveness and group valuation are primary sources of psychological group formation, along with common fate and mutual interdependence (Kramer and Brewer 1984; Rabbie and Horowitz

\footnotetext{
${ }^{9}$ Commitment is defined as the attachment of an individual to a relation, group, organization, or some other social unit (Kanter 1968). There are various behavioral forms this might take. A standard form is continuing exchange with the same others (stay behavior); others we have included are unilateral gift giving and investing in a new venture (Lawler and Yoon 1993, 1996, 1998). We focus on gifts and investment in a social dilemma for theoretical reasons, but we also analyze the continuance form of commitment behavior.
} 
American Journal of Sociology

1988; Kramer 1991, 1993). Thus, the main ingredients for psychological group formation are embedded in the productive form of exchange (interdependence and common fate) and manifest in the theoretical model we test (group distinctiveness and group evaluation). If a salient group boundary and person-to-group bonding are bases for group-oriented commitment in productive exchange, we should observe two separate but converging endogenous processes through which actors develop collective orientations and become willing to act with reference to the group.

To summarize, the theory predicts that greater interdependence and equality of dependence on the group promotes person-to-group commitments, indirectly and endogenously, through the following steps: (1) High interdependence and equal dependence generate more frequent exchange among actors. (2) More frequent exchange among these actors increases (a) positive emotions or feelings and $(b)$ the perceived predictability of the others. (3) Positive emotions and perceptions of predictability each make the relation more salient as a unifying, cohesive object in the situation. (4) Greater perceived cohesion produces more commitment to group, as reflected in unilateral gift giving among members and inclinations to undertake new collaborations that involve risk or the potential for malfeasance. The theoretical model specifies a series of interconnected bivariate hypotheses shown in figure 3 .

\section{METHOD}

\section{The Productive Exchange Context}

Several features of the experimental setting were designed to create a productive exchange context as conceptualized in the introduction. First, three actors were deciding whether to engage in a collaborative effort that was likely to produce more profits than they could achieve alone or in any other group available to them. The instructions explained that this profit was produced from a three-way research and development project that required the assent of all three actors. Second, coordination problems existed because actors did not exchange offers and counteroffers directly with the others, as in a negotiated exchange setting, but instead made claims on a pool of group-generated resources. The claims were made simultaneously and independently, which enhanced the coordination problems. Third, subjects in this new setting were deciding whether to participate in a collaborative venture, which is the person-to-group production of benefit, and what to claim in return for their participation, which is the group-to-person distribution of benefit. The procedures of the research adapted the dyadic negotiated exchange procedures of Lawler 
and Yoon $(1993,1996)$ to establish a three-person, productive exchange context.

The theory was tested with two distinct experiments, each tied to a different form of commitment behavior. The first experiment investigated the tendency to give small token gifts; the second focused on contribution behavior in an $N$-person social dilemma. In keeping with our theoretical scope, both experiments involved three subjects who repeatedly could negotiate a productive exchange under conditions of varying power and dependence. Their negotiation task was to allocate profits from a collaborative effort.

Design and Subjects

Each experiment employed the same $2 \times 2$ factorial design, manipulating dependence inequality (equal vs. unequal) and total dependence (high vs. low). Subjects were undergraduate students at a large eastern university who signed up in courses as paid volunteers. A total of 384 subjects participated in the two experiments. In each experiment, 64 same-sex triads (32 female, 32 male) were randomly assigned to one of four experimental conditions (16 triads per cell; 192 subjects per experiment).

\section{Procedures}

Upon their arrival, subjects were ushered into separate cubicles where they received written instructions. These explained that each person in the study would represent one of three research organizations-termed alpha, beta, and gamma. Each of the organizations purportedly developed highly specialized computer chips for sale to larger corporations. The instructions indicated that because of an increasingly competitive and uncertain market situation, each company must rely on joint research and development with other organizations to develop a competitive product. The cover story further explained that the three organizations have assembled the capital and talent to consider a joint venture of this type. Each subject was told that their task in the study was to negotiate for a share of the profits produced by the joint venture.

The subjects were told the study would simulate up to 20 negotiation episodes, defined as "years." The experiments actually ended after the sixteenth episode (year) to preclude "end effects." The instructions explained that because of changing market conditions, the profit divisions from the joint venture must be negotiated anew each year. In the event the three representatives could not reach an agreement, each could automatically secure an agreement with an alternative group where the profit was likely to be somewhat lower. Each representative had information 


\section{American Journal of Sociology}

only on the profits they earned given an agreement, a condition that is consistent with related work (Lawler and Bacharach 1987; Lawler and Yoon 1993, 1996). Subjects' pay depended on the agreements they reached with one another or with an alternative organization. When the experiment was complete, the assistant explained the nature of the research, answered questions, and paid the subjects using a standard formula that converted profit points to money.

The negotiations involved each actor claiming a portion of the profit from the joint venture. These claims were lodged simultaneously, so none knew the claims currently being made by the others. The instructions indicated that the total profit the three companies would produce was 1,625 points per year. The subjects were to negotiate on behalf of their organization in an effort to receive as much of the total profit as they possibly could.

The actual bargaining took place via microcomputers connected to each other from separate cubicles. Each episode (year) consisted of a maximum of five bargaining rounds. In turn, each round consisted of a single claim (from the 1,625 points) by each person. To make a claim, each person simply indicated (in multiples of 25) how many profit units their organization wished to claim. For any given round, the subjects could repeat their previous claim or make a concession by lowering their claim. They could not retract earlier concessions, that is, subjects could not raise their claims. An agreement occurred when the sum of the three claims were equal to or less than the joint profit (e.g., 1,625). The negotiation continued until an agreement was reached or until the end of the fifth round, whichever came first. If an agreement was not reached by round 5, each representative earned zero points from the focal group and was awarded an agreement with their simulated alternative group. This alternative payoff involved a random drawing, with the likelihood of different profits being based on a probability distribution that was used to manipulate relative and total levels of power dependence.

\section{Experimental Manipulations}

We manipulated structural power by varying the probability of various payoffs from the alternative group (see Lawler and Bacharach 1987; Lawler and Yoon 1993, 1996). The total power of actors was manipulated by varying the average quality (expected value) of alternatives across the three subjects. In the low total power condition, the average expected payoff of the three actors from the given alternatives was 350 points, while in the high total power condition their expected payoff from their alternatives was 200 points. Power inequality was manipulated by varying 
the relative quality (expected value) of the three subjects' alternatives to the focal group.

In the high total and equal power condition, all subjects had alternatives worth the same expected value (200 points), as indicated above, and the same probability distribution. Specifically, from their alternative group, all three subjects had a $5 \%$ chance of 250 points, $15 \%$ chance of 225 points, $60 \%$ chance of 200 points, $15 \%$ chance of 175 points, and $5 \%$ chance of 150 points. In the low total and equal power condition, each subject had an alternative with an expected payoff of 350 points, as indicated above, and a probability distribution as follows: a $5 \%$ chance of 400 points, $15 \%$ chance of 375 points, $60 \%$ chance of 350 points, $15 \%$ chance of 325 points, and $5 \%$ chance of 300 points.

Under unequal relative power combined with high total power, the high power subject had an alternative with an expected value of 350 points (i.e., a $5 \%$ chance of 400 points, $15 \%$ chance of 375 points, $60 \%$ chance of 350 points, $15 \%$ chance of 325 points, and $5 \%$ chance of 300 points); the subject at the middle level of power had an alternative with an expected value of 200 points (i.e., a $5 \%$ chance of 250 points, $15 \%$ chance of 225 points, $60 \%$ chance of 200 points, $15 \%$ chance of 175 points, and $5 \%$ chance of 150 points); and the least powerful subject had an alternative with an expected value of 50 points (i.e., a $5 \%$ chance of 100 points, $15 \%$ chance of 75 points, $60 \%$ chance of 50 points, $15 \%$ chance of 25 points, and $5 \%$ chance of 0 points). Under unequal dependence combined with low total dependence, a constant of 150 points was added to each point along the probability curve. This yielded expected values of 500, 350, and 200 points for the high, middle, and low power actors, respectively. ${ }^{10}$

\footnotetext{
${ }^{10}$ Following Emerson's $(1972,1981)$ power dependence theory, we see power as related to levels of dependence on the group. The more dependent a given actor, the less powerful. In turn, each actor's dependence $\left(D_{A}, D_{B}\right.$, and $\left.D_{G}\right)$ is the difference between the maximum potential payoffs in the group (i.e., $1625 / 3=542$ points) and individual member's expected value of alternative. In the low total power and unequal power condition described above, each actor's dependence is 342 (i.e., $542-200=342$ ), 192 (i.e., $542-350=192$ ), and 42 (i.e., $542-500=42$ ). The total dependence in this condition is the average of the three members' dependence on the group (i.e., 576/ $3=192$ ). Note that total dependence here is the same as the total dependence in the equal relative, low total power condition (i.e., $[192+192+192] / 3=193$ ). Relative power is defined in terms in dependence inequality, the average difference of each member's dependence (i.e., [ $\left.\left|D_{A}-D_{B}\right|+\left|D_{B}-D_{G}\right|+\left|D_{G}-D_{A}\right|\right] / 3$ ). For example, dependence inequality in the low total and unequal power condition is 200 (i.e., $[|342-192|+|192-42|+|42-342|] / 3=200$ ), which is also the same as dependence inequality in the high total and unequal power condition (i.e., [|492 $342|+| 342-192|+| 192-492 \mid] / 3=200)$.
} 
American Journal of Sociology

Dependent Measures

Both forms of commitment behavior (gift giving and investment) were measured at the triadic level. Subjects had the option to give small token gifts to one another (experiment 1) or contribute some of their individual resources into a single joint venture that is shared by all (experiment 2). These options were made available at the beginning of the thirteenth episode (year). Additional instructions were given to subjects following the twelfth episode to explain the options.

Gift behavior (experiment 1). - In the first experiment, commitment was measured by the propensity for the individuals to give one another gift vouchers. The gifts in this study were token (that is, worth very little monetarily), unilateral (given without knowing whether the other would reciprocate), and noncontingent (there was no clear reason for subjects to expect the others would reciprocate). In short, the gifts were more expressive than instrumental or strategic. ${ }^{11}$

Beginning at the end of episode 13 and continuing through the end of episode 16, each subject could provide gifts to one or both of the other representatives. The instructions explained: "The gift option is an chance to express how you feel about your relationship with the other two members ... whether or not you decide to give a gift is completely up to you and the gift vouchers you do not give become yours to keep." Two gift vouchers were given to the subjects at the close of negotiation for each gift episode. The subjects could then give these gifts to the other representatives or keep them for themselves by pressing the appropriate key on their keyboard. Subjects did not find out if others gave them gifts until the end of all negotiations, at which time the experimenter exchanged a piece of candy for each gift voucher held by each subject. This was to ensure that subjects did not treat gifts as an explicit part of the focal exchange. We use the ratio of gift giving frequency over the total number of possible gifts during the last four episodes to index the aggregate level of gift giving. This measure could range from 0 to 1 (mean $=.32 ; \mathrm{SD}=$ .14).

Contribution behavior (experiment 2). - In the second experiment, commitment was measured by the tendency to invest in a new joint venture that involved considerable risk and the potential for malfeasance. As noted above, this joint venture took the form of a $N$-person prisoner's dilemma game. Beginning at the end of episode 13 and continuing through episode

\footnotetext{
${ }^{11}$ Heath (1975) contrasts three forms of gift giving: presents, favors, and donations. Presents are a symbol of a positive, friendly relationship, favors provide a service to another, whereas donations are directed at a goal shared by the giver and receiver. Gifts in our experiments are "presents" in Heath's (1975) terms. They are small, token gestures that symbolically put forth a definition of the relationship.
} 
16, subjects had the option of investing 200 points into a joint account co-owned by the three actors. This account would generate profit returns at $50 \%$ on the investment, and these would be divided equally among the three companies. All three had to contribute in order to generate the individual returns on investment. The individual earnings from the investment option were not reported to the subjects until the end of the experiment, which ensured that subjects could not determine how often others used the investment option. The individual earnings from the investment option were added to those from the productive exchange. ${ }^{12}$

In game-theoretic terms, this measure constitutes a decomposed prisoner's dilemma game (Rapoport and Chammah 1965) with the important difference that subjects did not know whether the others had contributed until the experiment was completed. Again, we calculated the ratio of actual contributions over the total number of possible contributions across episodes 13-16 to create an index of contribution behavior. This index could range from 0 to 1 (mean $=.36$; $\mathrm{SD}=.21$ ).

\section{Common Variables}

Several measures were common across the two experiments. Our software tracks the frequency of agreement and profit difference for each experimental session. ${ }^{13}$ We also administered a computerized questionnaire to measure positive emotion, predictability, and group cohesion. All common variables were indexed to form a triadic score, for which larger numbers indicate a higher level on the variable. Exchange frequency is inherently triadic, while positive emotion, predictability, and group cohesion are defined as the average of the individual scores. We address each measure in turn.

Exchange frequency.-The measure of exchange frequency is the proportion of negotiation episodes for which a given triad of actors reaches an agreement. We focus on the rate of agreement across the first 12 ep-

\footnotetext{
${ }^{12}$ If no one contributed to the joint account, then all three actors received no net gain for that year. In the event one member contributed and two did not, the 200 points invested turned into 300 points, which was then divided equally among the actors (i.e., the contributor lost 100 points and the two noncontributors each earned a net profit of 100 points). If two members contributed to the joint account, the contributors each earned a net profit of 0 points and the noncontributor earned a net profit of 200 points. Finally, if all three members contributed, each earned a net profit of 100 points (i.e., the 600 points invested becomes 900 to be divided equally between the three actors).

${ }^{13}$ The theory of relational cohesion makes no predictions for profit differences, and prior research has clearly shown the effect of exchange frequency is independent of profit differences (Lawler and Yoon 1996). As such, our analysis will focus on the effect exchange frequency has on the commitment process.
} 


\section{American Journal of Sociology}

isodes of negotiation, primarily because this phase represents the period during which the endogenous processes stipulated by the theory should develop. The average proportion of agreement across the first 12 episodes was slightly less than half (mean $=.42 ; \mathrm{SD}=.19$ ).

Positive emotions. - Subjects reported their feelings about the negotiations along a series of nine-point bipolar adjectives after episodes 6 and 12. The items and measures were previously developed by Lawler and associates (1993, 1995) using factor analytic techniques. These measures were later validated by confirmatory factor analyses in comparable research (Lawler and Yoon 1996, 1998). The items and measures used in the current research are virtually identical to those used previously (Lawler and Yoon 1993, 1996, 1998). The pleasure/satisfaction index consisted of self-report evaluations on four items: pleased/displeased, happy/ unhappy, satisfied/not satisfied, and contented/discontented (for all triads, mean $=4.2$ and 5.2; $\mathrm{SD}=1.13$ and 1.34; and Cronbach's $\alpha=.95$ and .97; respectively, at episodes 6 and 12). The interest/excitement index summed the following four items: interesting/not interesting, exciting/ boring, enthusiastic/unenthusiastic, and motivating/unmotivating (mean $=6.0$ and $6.1 ; \mathrm{SD}=.87$ and $.99 ;$ and Cronbach's $\alpha=.86$ and .92 ; respectively, at episodes 6 and 12).

Predictability.-After episodes 6 and 12, subjects were asked to characterize their negotiations with the others. We created a predictability index by summing the subjects self-reported perceptions on the following four items: predictable/unpredictable, certain/uncertain, clear/vague, and stable/fluctuating (mean $=5.95$ and $6.24 ; \mathrm{SD}=.87$ and .90 ; and Cronbach's $\alpha=.77$ and .84; respectively, at episodes 6 and 12).

Group cohesion.-This measure, reported after episodes 6 and 12, was a simple extension of the relational cohesion measure used in previous dyadic studies (Lawler and Yoon 1993, 1996). In that research, confirmatory factor analysis indicated that the relational-cohesion index was highly reliable and empirically distinct from the measures of emotion. Subjects were asked to describe their relationships with each of the others along a series of bipolar adjectives. The index included the following items: close/distant, coming together/coming apart, solid/fragile, and cohesive/divisive (mean $=4.40$ and 5.01; $\mathrm{SD}=.96$ and 1.15; and Cronbach's $\alpha=.86$ and .92; respectively, at episodes 6 and 12).

\section{RESULTS}

The theory specifies a priori a causal model that entails a sequence of steps, through which conditions of structural power indirectly lead to commitment behavior (see fig. 3). Based on the theory, the experimental 
methods and procedures impose the appropriate temporal order among the variables. Standardized experimental procedures, along with the randomization of groups to experimental conditions, establishes the controls that make possible causal inferences.

The theory makes strong claims about what empirical links will be found, that is, predicting effects only for theoretically contiguous variables. Our purpose is to test whether these are the primary or only links among variables in the model. If there are positive direct effects between steps (variables) that are not contiguous, for example, between total dependence and emotion or between emotion and commitment, revisions are needed in the theory to account for these additional paths.

We use linear structural equation modeling (Jöreskog and Sörbom 1993) to examine the overall fit of our measurement and theoretical model, and then we estimate the parameters associated with each theoretical path to determine if the hypothesized processes operate as predicted. This technique affords three primary advantages. First, the causal and the measurement models are specified such that the two are simultaneously estimated. The behavioral measures (exchange frequency, gift giving, investment) are single-indicator rates or proportions, whereas questionnaire measures (predictability, positive emotion, cohesion) are multipleindicator measures. The use of Lisrel allows us to take advantage of multiple indicators to correct for attenuation in the path estimates due to random measurement error (see Thye 2000). Second, to be consistent with theory and research on emotions (i.e., Russel 1980), we created a hypothetical second-order construct, termed positive emotion, with two subdimensions-interest/excitement and pleasure/satisfaction. Third, to correct for potential biases caused by unmeasured factors that share variance with predictability and positive emotion, the error terms of these constructs are allowed to be correlated with one another. This permits an unbiased estimate of effects from each construct to relational cohesion.

The presentation of the analysis is divided into four parts. First, we use confirmatory factor analysis to test the four-factor model assumed for the questionnaire indices: pleasure/satisfaction, interest/excitement, predictability, and cohesion. Second, we test the model up through group cohesion, combining data from both experiments since they are identical until episode 13 when subjects begin the commitment phase. Third, separate analyses for the two commitment behaviors (i.e., gift giving and contributing to a new venture) are conducted. Fourth, the data from these experiments are compared to the dyadic data collected in a previous negotiated exchange study (Lawler and Yoon 1996). 
American Journal of Sociology

TABLE 1

CONFirmatory Factor Analysis Results

\begin{tabular}{|c|c|c|c|c|c|c|c|}
\hline Measurement Model & $\chi^{2}$ & $d f$ & GFI & AGFI & LTI & CFI & RMSEA \\
\hline Independent model & 2,035 & 120 & & & & & \\
\hline \multicolumn{8}{|l|}{ One-factor model } \\
\hline$\{\mathrm{PR}+\mathrm{GC}+\mathrm{PS}+\mathrm{IE}\}$ & 810 & 104 & .52 & .37 & .59 & .63 & .23 \\
\hline \multicolumn{8}{|l|}{ Two-factor model } \\
\hline$\{\mathrm{PR}+\mathrm{PS}+\mathrm{IE}\} \mathrm{GC}\} \ldots \ldots$ & 634 & 103 & .59 & .46 & .68 & .72 & .20 \\
\hline \multicolumn{8}{|l|}{ Two-factor model } \\
\hline$\{\mathrm{PS}+\mathrm{IE}+\mathrm{GC}\}\{\mathrm{PR}\} \ldots \ldots$ & 642 & 103 & .58 & .44 & .67 & .72 & .20 \\
\hline \multicolumn{8}{|l|}{ Three-factor model } \\
\hline$\{\mathrm{PR}\}\{\mathrm{GC}\}\{\mathrm{PS}+\mathrm{IE}\} \ldots$ & 462 & 101 & .67 & .55 & .78 & .81 & .17 \\
\hline \multicolumn{8}{|l|}{ Four-factor model } \\
\hline$\{$ PR $\}\{$ GC $\}$ PS $\}\{I E\}$ & 152 & 98 & .88 & .84 & .97 & .97 & .06 \\
\hline
\end{tabular}

Note.-GFI, AGFI, LTI, CFI, RMSEA refer to goodness-of-fit index, adjusted goodness-of-fit index, Lewis-Tucker goodness-of-fit index, comparative fit index, and root mean square error of approximation, respectively; also PR, GC, PS, and IE refer to predictability, group cohesion, pleasure/satisfaction, and interest/excitement. All $\chi^{2}$ and factor loading values are statistically significant at $P<.001 ; N=128$.

\section{Confirmatory Factor Analysis}

Table 1 contains the results of a confirmatory factor analysis. The theory posits a four-factor model by distinguishing the two self-reported emotions, perceived predictability, and perceptions of group cohesion. Theoretically, the main alternative to this model is a three-factor model in which the two emotions (pleasure/satisfaction and interest/excitement) are combined. A number of other specifications are logically possible but less likely given the distinctiveness of these constructs in past research (Lawler and Yoon 1996, 1998). Table 1 contains results for the most plausible models, given our theory and past research. There is strong support for the four-factor model. In fact, only the four-factor model reaches goodnessof-fit levels that are consistently high across the various fit measures (GFI $=.88 ; \mathrm{AGFI}=.84 ; \mathrm{LTI}=.97 ; \mathrm{CFI}=.97 ; \mathrm{RMSEA}=.06)$. Thus, there is clear empirical support for key conceptual distinctions made by the theory. Having demonstrated the distinctiveness of the theoretical constructs, we next test for both endogenous processes simultaneously. ${ }^{14}$

${ }^{14}$ All of the items loaded significantly on hypothesized factors (see also Lawler and Yoon 1993, 1996, and 1998). An examination of the cross-loadings and measurement errors did not show any abnormal patterns, suggesting the measurements are valid. For pleasure/satisfaction, the item factor loadings are $.92, .95, .97$, and .96 respectively for pleased/displeased, unhappy/happy, unsatisfied/satisfied, and discontented/ contented. For interest/excitement, the loadings were $.83, .86, .92$, and .86 respectively for not interesting/interesting, boring/exciting, unenthusiastic/enthusiastic, and unmotivating/motivating. For predictability, they were $.74, .89, .63$, and .78 respectively for unpredictable/predictable, uncertain/certain, vague/clear, and fluctuating/stable. Finally, the loadings for group cohesion were $.84, .89, .86$, and .89 for distance/close, coming apart/coming together, fragile/solid, and divisive/cohesive. 
Productive Exchange

\section{Group Cohesion Model}

Figure 4 contains the standardized Lisrel coefficients for the indirect paths hypothesized from structural power-to-group cohesion. In this and subsequent analyses, the exogenous power-dependence conditions are dummy variables and both emotions (pleasure/satisfaction and interest/excitement) are treated as indicators of the broader second-order construct, positive emotion. As indicated before, the path and measurement models were estimated simultaneously. We examine each prediction of the theory in the appropriate sequence below.

\section{Power Dependence and Exchange Frequencies}

The hypotheses linking power to exchange frequency were supported (see table 2). The results as seen in figure 4 indicate that higher total or mutual dependence on the group increased the frequency of exchange $(\beta=.33$; $P<.01$ ), and equal compared to unequal power has a comparable positive effect $(\beta=.21 ; P<.05)$. These findings are consistent with the predictions and with past research (see Lawler and Yoon 1996). There is also a significant interaction effect $(\beta=-.27 ; P<.05)$, which suggests that the lowest frequency of exchange was when power was unequal and mutual dependence was low. ${ }^{15}$

It is important to note that these results suggest that the awareness of power dependence conditions, other than one's own, is unnecessary for the predicted structural-power effects on exchange frequency. The reason is that subjects in this research did not have full information about the power (alternative) conditions. Each person knows that all individuals have an alternative, but they do not have details about the nature of this alternative, which they did have in previous research on dyadic negotiated exchange (Lawler and Yoon 1993, 1996, 1998). Thus, we affirm a point made by early research on exchange networks (Cook et al. 1983)—namely, that structural power effects are present even when actors are unaware of their comparative power positions.

\footnotetext{
${ }^{15}$ The pattern of interaction indicates that under low total power conditions, subjects in the equal power condition reached more agreements than those in the unequal power condition (.42 vs. .35). However, there was a nonsignificant trend in the opposite direction within the high total power conditions (.43 vs. .46). This interaction effect has not been evident in four previous experiments with dyads, so it is not clear whether this effect is unique to triadic productive exchange or a function of the limited information concerning the alternative payoff available to other negotiators. The presence of the theoretically posited main effects is sufficient for our purposes here-namely, to test the core of the theory that explains how exchange frequencies alter the commitment process.
} 


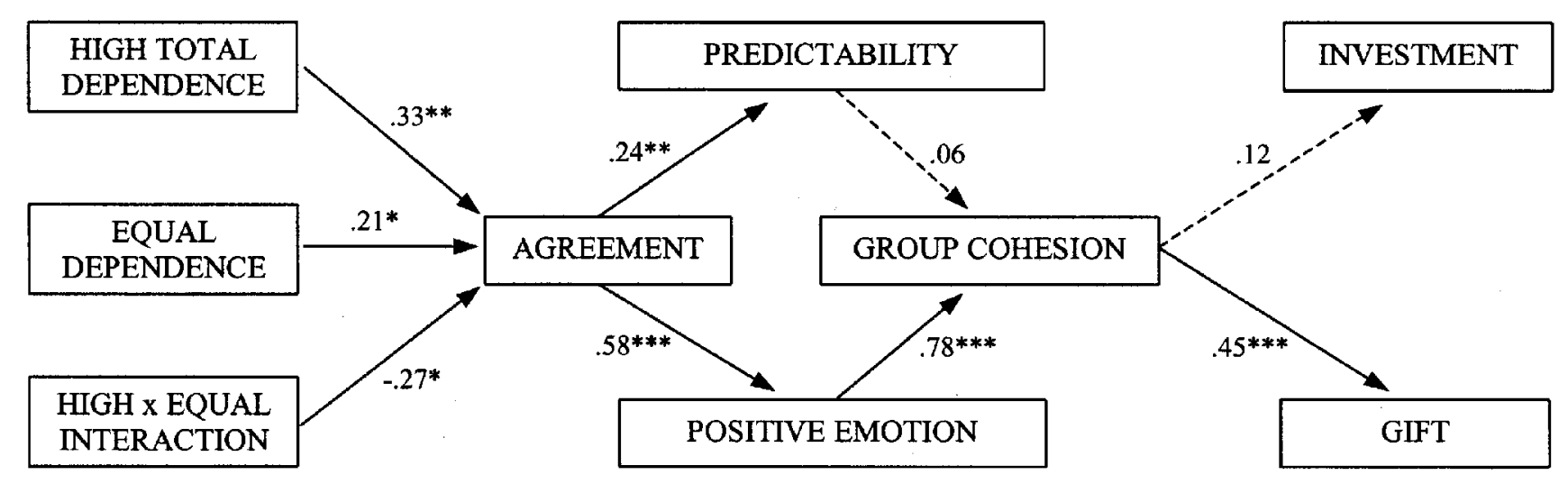

Fig. 4.-Results from the original model. ${ }^{*} P<.05 ;{ }^{* *} P<.01 ;{ }^{* * *} P<.001$. 
Productive Exchange

Test of Endogenous Process

Exchange frequency, positive emotion, and predictability.-Next, we test for the first step in the endogenous process, that is, the predicted positive effects of exchange frequency on positive emotion (i.e., pleasure/ satisfaction and interest/excitement) and on the perceived predictability of the negotiations. The results reveal strong support for the central predictions of relational cohesion theory. Table 2 (second and third columns) shows that when actors successfully exchange more frequently, they experience stronger positive feelings $(\beta=.58 ; P<.001)$; in addition, they perceive more predictability in negotiations with the focal group $(\beta=$ $.24 ; P<.01)$. When pleasure/satisfaction and interest/excitement are analyzed separately, we find stronger effects for pleasure/satisfaction $(\beta=$ $.58 ; P<.001)$ than interest/excitement $(\beta=.32 ; P<.001)$, but exchange frequency significantly affects both. ${ }^{16}$ Overall, the results for exchange frequency support the first "moment" or step in the parallel endogenous processes.

Group cohesion.-The hypothesized effects of emotion and predictability on perceived group cohesion are a critical part of the endogenous process, where group formation on a cognitive level is most likely to be located. Results for the emotion-to-cohesion link strongly affirm the hypothesis $(\beta=.78 ; P<.001)$, but results for the predictability-to-cohesion link do $\operatorname{not}(\beta=.06 ; \mathrm{NS})$. Thus, we find clear evidence for the emotional/ affective mechanism but no evidence for the uncertainty-reduction mechanism. These findings support the original version of relational cohesion theory (Lawler and Yoon 1996) and demonstrate the independence of the emotional/affective process and the uncertainty reduction process favored by most exchange theorists. The implication is that the emotional/affective mechanism is more important to the emergence of a "collective sense" at the relational or group level.

To further examine this, we included an indicator of subjective group value, that is, a set of bipolar adjectives measuring the degree that the group was valuable/not valuable, precious/not precious, and significant/ insignificant (Cronbach's $\alpha=.91$ ). We conducted an analysis that predicted subjective group value from the variables in the endogenous process, that is, from agreement frequency, positive emotion, predictability, and cohesion. The results indicate that perceived cohesion has the largest effect on subjective group value, controlling for all other variables in the theoretical model $(\beta=.76 ; P<.001)$. We also analyzed a single item on

${ }^{16}$ The stronger effect of pleasure/satisfaction can also be inferred indirectly from the second-order confirmatory factor structure. The second-order confirmatory factor analysis shows that the factor loading from positive emotion to pleasure satisfaction is .96, while that from positive emotion to interest/excitement is .53. 
American Journal of Sociology

TABLE 2

Standardized Lisrel Estimates of the Causal Paths in the

Theoretical Model: Triads

\begin{tabular}{|c|c|c|c|c|c|c|}
\hline Independent & $\mathrm{AF}$ & $\mathrm{PE}$ & PR & $\mathrm{GC}$ & Gift & Investment \\
\hline High total power (HT) & $.33^{* *}$ & & & $\cdots$ & & \\
\hline Equal power $(\mathrm{EQ}) \ldots \ldots \ldots \ldots$ & $.21^{*}$ & $\ldots$ & . & $\ldots$ & & $\ldots$ \\
\hline 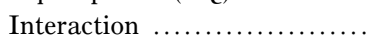 & $-.27^{*}$ & . & & $\ldots$ & & $\ldots$ \\
\hline Agreement frequency (AF) ... & $\ldots$ & $.58^{* * *}$ & $.24^{* *}$ & $\ldots$ & & $\ldots$ \\
\hline Positive emotion (PE) $\ldots \ldots \ldots$ & . & $\ldots$ & $\ldots$ & $.78 * * *$ & & $\ldots$ \\
\hline Predictability (PR) & $\ldots$ & $\ldots$ & $\ldots$ & .06 & & $\ldots$ \\
\hline Group cohesion (GC) & . & $\ldots$ & $\ldots$ & . & $.45^{* * *}$ & .12 \\
\hline$R^{2}$ & .06 & .34 & .06 & .65 & .20 & .01 \\
\hline$\chi^{2}$ & 306.60 & & & & & \\
\hline
\end{tabular}

Note. $-N=128$. For $\chi^{2}, P=.00 ; d f=200$. Goodness of fit $=.84$; Lewis-Tucker fit index $=.94$; comparative fit index $=.95$.

$* P<.05$, one-tailed tests.

** $P<.01$.

*** $P<.001$.

the poststudy questionnaire that asked subjects to what extent the three of them "belonged to the same group." Again, controlling for all other variables in the model, greater perceived cohesion significantly increased the sense of being part of the same group $(\beta=.34 ; P<.01)$. Thus, the endogenous process does generate a sense of groupness. The results for perceived value and perceived groupness add further weight to the underlying assumptions and logic of the theory.

To summarize, results for the endogenous process support key elements of the theory of relational cohesion. There is strong support for the idea that frequent productive exchange unleashes an emotional affective process that generates a sense of groupness (cohesion). Frequent exchange produces positive emotions, which in turn, produce greater perceived cohesion. Moreover, the results demonstrate that this emotional/affective process is independent of and, in fact, stronger than the uncertainty reduction process. Frequent exchanges reduced uncertainty, as expected, but our research suggests that emotions are the primary foundation for group formation. This does not imply that we have refuted the uncertainty reduction explanation for commitment proposed by Kollock (1994) and others (Cook and Emerson 1984). Rather, it suggests that uncertainty reduction does not operate through the group formation process specified here. Momentarily, we pursue an alternative process for uncertainty reduction. 


\section{Commitment Behavior}

The final theoretical link connects perceived cohesion to behavioral acts of commitment. The results (fig. 4 and table 2) indicate that group cohesion increases the rate of unilateral gift giving among the actors as predicted by the theory $(\beta=.45 ; P<.001)$. However, in the case of actors' propensity to invest in a new joint venture, there is a weak effect in the right direction $(\beta=.12)$, but it does not reach statistical significance $(P<.11)$. The failure to find a significant effect contrasts with previous work on dyadic exchange, which observed cohesion-to-commitment effects on a range of commitment-type indicators including stay, gift giving, and investment behaviors.

To determine whether this departure is unique to our measure of investment in a social dilemma, we examined the proportion of agreements between rounds 13 and 16 as a proxy for stay behavior or "continuance commitment" in Kanter's (1968) terms. Continued exchange was treated as another form of commitment behavior, and the analysis was identical to that for gift giving and investment. The results are virtually identical to those for gift giving. When all antecedent variables of the theory (fig. 3) plus profit differences are controlled, there are two significant effects: a positive effect for perceived group cohesion $(\beta=.21 ; P<.05)$ and a positive direct effect for exchange frequency $(\beta=.31 ; P<.01)$. The first is consistent with relational-cohesion theory and with previous research (Lawler and Yoon 1993, 1996). The second is a common residual effect for exchange frequency that tends to show up consistently in related research (see Lawler and Yoon 1993, 1996). The investment form of commitment behavior stands out as the only form not affected by group cohesion.

One important difference in this study is that the investment decision involved an $\mathrm{N}$-person prisoner's dilemma game, whereas dyadic research involved a two-person prisoner's dilemma. It is well known that cooperation is harder to generate in the former. The implication of these results, however, is that different social processes may be producing different

forms of commitment behavior. For example, there could be dual processes operating to produce commitment: an expressive one captured by gift giving and an instrumental one captured by a propensity to invest in a social dilemma. In the following section, we consider this possibility.

\section{A Modified Model}

To consider if a dual process operates, we examined a modified model with a direct path from perceived predictability to investment behavior (see table 3). Adding this path was a reasonable alternative specification, 
American Journal of Sociology

TABLE 3

Standardized Lisrel Estimates of the Causal Paths in the Modified Model: Triads

\begin{tabular}{|c|c|c|c|c|c|c|}
\hline Independent & $\mathrm{AF}$ & $\mathrm{PE}$ & PR & $\mathrm{GC}$ & Gift & Investment \\
\hline High total power (HT) & $.33^{* *}$ & $\ldots$ & $\ldots$ & & $\ldots$ & \\
\hline Equal power $(\mathrm{EQ}) \ldots \ldots \ldots \ldots$ & $.21^{*}$ & . & . & & . & \\
\hline Interaction $\ldots \ldots \ldots \ldots \ldots \ldots$ & $-.27^{*}$ & & & & & \\
\hline Agreement frequency (AF) ... & & $.58 * * *$ & $.24^{* *}$ & & $.24^{* *}$ & $.22^{* *}$ \\
\hline Positive emotion (PE) ....... & . & $\ldots$ & $\ldots$ & $.77^{* * * *}$ & $\ldots$ & \\
\hline Predictability $(\mathrm{PR}) \quad \ldots \ldots \ldots \ldots$ & $\ldots$ & $\ldots$ & $\ldots$ & .06 & & $.30^{* *}$ \\
\hline Group cohesion $(\mathrm{GC}) \ldots \ldots \ldots$ & & $\ldots$ & . . & & $.33^{* * * *}$ & -.12 \\
\hline$R^{2} \ldots \ldots \ldots \ldots \ldots$ & .06 & .34 & .06 & .64 & .24 & .13 \\
\hline$\chi^{2}$ & 284.90 & & & & & \\
\hline
\end{tabular}

Note. $-N=128$. For $\chi^{2}, P=.00 ; d f=197$. Goodness of fit $=.84 ;$ Lewis-Tucker fit index $=.95$; comparative fit index $=.96$.

$* P<.05$, one-tailed tests.

** $P<.01$.

*** $P<.001$.

given research on uncertainty by other exchange theorists (see Cook and Emerson 1984; Kollock 1994) and also because modification indices suggested such a path. We chose to add two other direct paths as well: one from exchange frequency to gift giving and one from exchange frequency to investment behavior. Previous research has shown residual (and positive) direct effects from exchange frequency to commitment behavior, though these have not always reached significance (e.g., Lawler and Yoon 1993, 1996), and again the modification indices suggested these paths. All three of these new paths attained a conservative significance level of at least $P<.01$ in the modification indices.

The revised model with these additional links is in figure 5. The most important finding is the direct path from predictability to investment behavior $(\beta=.30 ; P<.01)$. This is theoretically interesting because a positive impact here can be interpreted in terms of perceived trust, defined as a general expectation of cooperation (Pruitt and Kimmel 1977). Before trust can emerge between two individuals, each must view the other as predictable. In this sense, predictability is an essential condition for the development of trust. If indeed predictability and trust are related in this way, and trust is necessary for investment in a social dilemma situation, then we would expect a positive significant path between predictability and investment behavior, as we observe.

Turning to the direct effects from exchange frequency to gift giving, and from exchange frequency to investment, we have speculated in the past that this may reflect the uncertainty reduction process, but since uncertainty reduction is measured and controlled here, there must be 
$.22^{* *}$

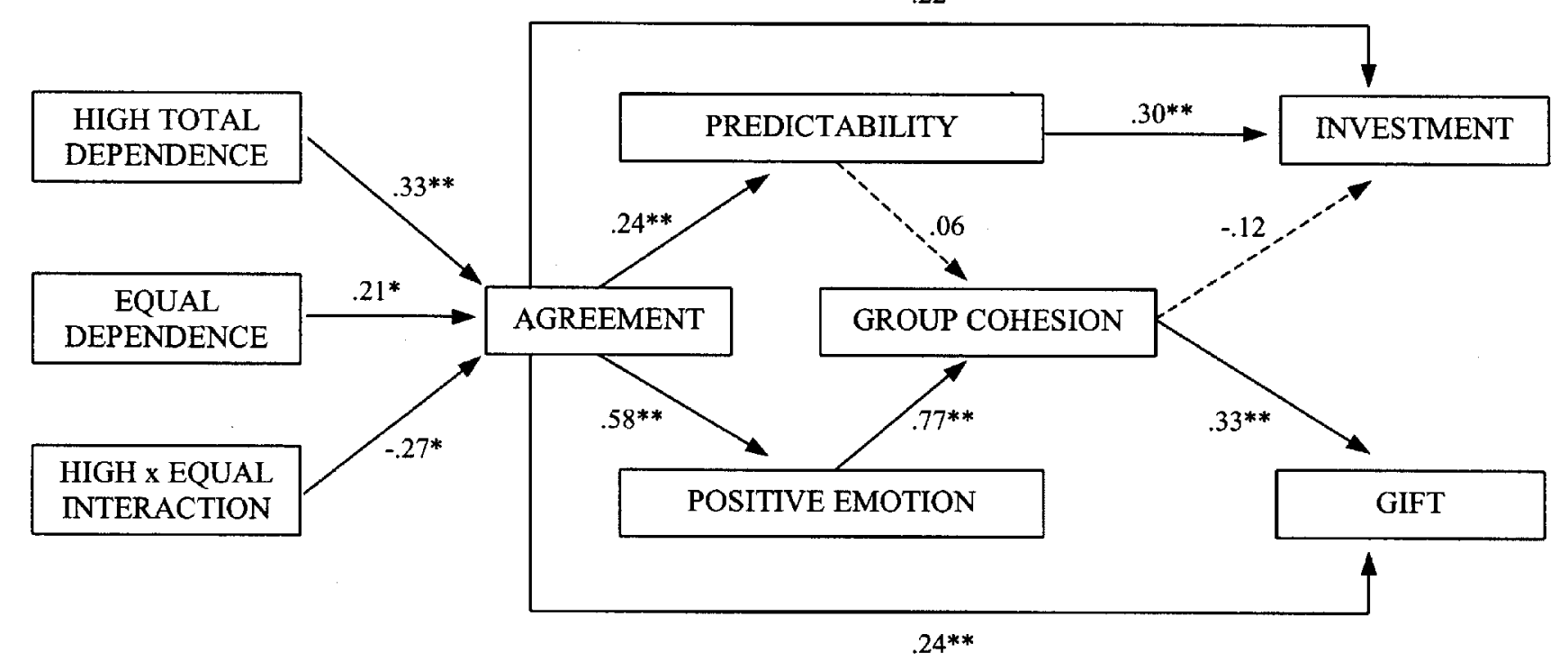

Fig. 5. - Results from the refined model. ${ }^{*} P<.05 ;{ }^{* *} P<.01$. 
American Journal of Sociology

another mechanism at work. One plausible interpretation is that this is a noncognitive reinforcement process. Said differently, actors who are rewarded for exchanging in the first 12 episodes may tend to repeat these cooperative behaviors, in the form of various commitment behaviors. If social reinforcement processes are operating, above and beyond other processes in the theory, then we would expect to see direct effects between exchange frequency and commitment behaviors, and we do.

It is important to note that while three new paths were added, there were no major changes to any of the original paths. The results, therefore, reveal a dual commitment process: (1) an affective process that generates symbolic forms of commitment such as gift giving (Lawler and Yoon 1996), and (2) an uncertainty reduction process (Kollock 1994) that generates more willingness to risk cooperative behavior in an $N$-person social dilemma. Actors give more gifts to each other when successful exchange makes them feel good and when they perceive an emerging feeling of unity among members. Investment behavior, on the other hand, requires trust in exchange partners (Kollock 1994), especially in an $N$-person dilemma, and this is reflected in the impact that frequent exchange has on perceived predictability and that perceived predictability has on investment. These results suggest parallel instrumental and expressive group formation processes.

\section{A Comparison to Previous Research}

Because the procedures of experiments in Lawler and Yoon (1996) are nearly identical, except for the context (i.e., person-to-person negotiated vs. person-to-group productive exchange), we have the opportunity to explore differences between dyadic negotiated exchange and triadic productive exchange across experiments. Overall, we would expect exchange frequencies to be lower in triadic productive exchange due to coordination problems, and this in turn should be manifest in lower levels of positive emotion, predictability, cohesion, gift giving, and investment behavior.

To test for such effects, we conducted $t$-tests for two samples comparing the grand means for the dyad and triad experiments. The results, in table 4 , reveal patterns in the expected direction across nearly all the theoretical variables. In the case of behavioral variables, the exchange frequency in triadic productive exchange was roughly two-thirds of that observed in dyadic negotiated exchange; fewer gift opportunities were used in triads than dyads; and fewer contributions or investments also were made in triads than dyads. These comparisons affirm that cohesion and commitment are more problematic in the multiactor productive context than in the negotiated dyadic context. In the case of emotion and cohesion, both forms of positive emotion are significantly lower in triadic than in dyadic 
Productive Exchange

TABLE 4

$t$-test of the Key Variables between the Dyad and Triad Study

\begin{tabular}{|c|c|c|c|}
\hline Variable & Mean for Dyads & Mean for Triads & $t$-test (Dyad-Triad) \\
\hline Agreement frequency ........ & $\begin{array}{l}.62 \\
(.20)\end{array}$ & $\begin{array}{l}.42 \\
(.19)\end{array}$ & $9.59^{* * * *}$ \\
\hline Pleasure/satisfaction & $\begin{array}{c}5.56 \\
(1.28)\end{array}$ & $\begin{array}{c}5.19 \\
(1.34)\end{array}$ & $2.64^{* *}$ \\
\hline Interest/excitement . & $\begin{array}{c}6.34 \\
(.98)\end{array}$ & $\begin{array}{l}6.11 \\
(.99)\end{array}$ & $2.17^{*}$ \\
\hline Positive emotion .... & $\begin{array}{c}5.95 \\
(1.01)\end{array}$ & $\begin{array}{c}5.65 \\
(1.00)\end{array}$ & $2.76^{* *}$ \\
\hline Relational/group cohesion ... & $\begin{array}{l}5.12 \\
(.91)\end{array}$ & $\begin{array}{c}5.01 \\
(1.15)\end{array}$ & .94 \\
\hline Gift exchange ................ & $\begin{array}{c}.49 \\
(.20)\end{array}$ & $\begin{array}{c}.32 \\
(.14)\end{array}$ & $5.56^{* * * *}$ \\
\hline Investment & $\begin{array}{c}.50 \\
(.27)\end{array}$ & $\begin{array}{l}.36 \\
(.21)\end{array}$ & $3.33^{* * *}$ \\
\hline
\end{tabular}

NotE. - The number of cases for the variables gift giving and investment are 64 and 80, respectively, for the dyad study and the triad study. Gift exchange and investment for both studies are measured as the ratio of exchanged gifts or contributed investments out of the total possible chances. SDs are given in parentheses. $N=240$ for dyads; $N=128$ for triads.

$* P<.05$, one-tailed tests.

*** $P<.01$.

*** $P<.001$.

exchange, as we expected, while the difference in perceived cohesion is in the correct direction but not significant. In sum, the triadic productive structure generated lower exchange frequencies, lower levels of positive feeling, but about the same level of perceived cohesion.

We also analyzed for changes over time, comparing the first and second administrations of the questionnaire. In triadic productive exchange, exchange frequency (mean $=.30-.53 ; t=10.44 ; P<.001$ ); pleasure/ satisfaction (mean $=4.2-5.2 ; t=7.47 ; P<.001$ ), and group cohesion (mean $=4.40-5.01 ; t=5.81 ; P<.001$ ) were all higher after episode 12 than after episode 6 . In fact, among the theoretical variables, only interest/ excitement failed to increase from the first to the second part of the experiment. In dyadic negotiated exchange, differences across time did not occur; only small differences were observed across time (mean $=5.9-.65$ for exchange frequency; 5.3-6.3 for pleasure/satisfaction; 5.5-6.3 for interest/excitement). The upshot is that the endogenous process tends to become stronger over time in multiactor productive exchange, whereas in dyadic negotiated exchange, the levels of exchange frequency, emotion, and cohesion were established early and then maintained.

Overall, these exploratory and rather global comparisons of our triadic research here with dyadic exchange in previous research (Lawler and Yoon 1996) have two general implications. First, cohesion and commit- 
American Journal of Sociology

ment are more problematic in multiactor productive exchange than in dyadic negotiated exchange, and this is manifest in less pleasure/satisfaction and lower rates of commitment behavior. Second, the exchangeto-emotion-to-cohesion process specified by the theory tends to start lower and grow in strength over time in the multiactor productive case, whereas a stable level is reached more quickly in the dyadic negotiated case.

\section{DISCUSSION}

\section{Overview}

This research was undertaken with two primary objectives: first, to extend the theory of relational cohesion to multiactor, productive exchange in which three actors have an incentive to negotiate a joint venture; second, to test two alternative explanations for the development of group commitment in productive exchange-uncertainty reduction and positive emotion. Both questions address how it is that commitment and rudimentary group formation, involving person-to-group attachments (Kanter 1968; Hall 1988), emerge from repeated exchange among multiple actors. We propose that productive exchange generates group attachments by focusing actors' attention on the collective nature of their task and through the joint responsibility they have for success or failure at exchange.

As far as we know, this is the first study explicitly concerned with productive exchange. Productive exchange is characterized by higher degrees of mutual interdependence than other forms of exchange -negotiated, reciprocal, and generalized (see Molm 1994; Molm and Cook 1995). The rational course in productive exchange is to transact, and the main obstacle is coordination (Schelling 1960). In other words, productive exchange strengthens the cooperative elements and weakens the competitive elements of a mixed-motive context, primarily because of the underlying interdependencies that characterize this form of exchange. Relational cohesion theory (Lawler and Yoon 1993, 1996) can elaborate the consequences of this structure.

The main results of this research generally support predictions from relational-cohesion theory. First of all, total or average dependence on the group (i.e., sum of each person's group dependence) and equal, rather than unequal, dependence increase the frequency of productive exchange; these effects occur even though individuals do not know others' power position and therefore cannot compare their own dependence on the group to the others' (see Cook et al. [1983] and Markovsky, Willer, and Patton [1988] for similar structural effect in exchange networks). Second, as revealed by earlier studies of negotiated exchange, more frequent productive exchange generates positive emotions that, in turn, enhance perceptions 
of group cohesion. Exchange frequency also has the predicted positive effects on the perceived predictability of negotiations with the others, but contrary to the theory, predictability does not enhance perceived group cohesion. Third, as predicted, greater perceived cohesion increases commitment behavior for gift-giving to other members and also for continuing to exchange with them (staying). Greater cohesion, however, does not enhance the propensity of group members to invest in a more risky joint venture that could lead to malfeasance or exploitation by the others.

\section{Dual Processes of Commitment}

Our findings point to an important departure from the theory that warrants attention. Specifically, despite evidence that more frequent exchange increases the perceived predictability, predictability does not increase perceptions of group cohesion. This calls into question the hypothesized mediating role of uncertainty reduction. One plausible interpretation is that there are dual processes promoting commitment to groups, manifest in different commitment behaviors. That is, different forms of commitment behavior may be produced through different mediating steps or processes.

In support of this idea, our data reveal that the relational-cohesion process occurs for gift giving and for continuing exchange (stay behavior), whereas investments in a new joint venture (i.e., a social dilemma) are generated by uncertainty reduction, but not through group cohesion. This suggests that a trust process may be operating to produce commitment in addition to the emotional/affective process. Exchange-theoretic analyses of uncertainty reduction, in fact, tend to treat trust as a key mediating condition for uncertainty reduction. As uncertainties about the others are reduced, predictions about when they will or will not cooperate develop a firmer foundation, that is, there is an increase in "expectations of cooperation by others" (Pruitt and Kimmel 1977; Yamagishi 1995; Kramer and Tyler 1996). Predictability and trust are not one and the same, because others may be predictably unreliable, malevolent, or untrustworthy. Nevertheless, the causal chain we observe (exchange frequency $\rightarrow$ perceptions of predictability $\rightarrow$ investment in a social dilemma) can be interpreted as a perceived-trust mechanism that is distinct from an emotionbased group formation mechanism. In this sense, our research tends to suggest dual processes through which person-to-group commitments develop in multiactor, productive exchange. This is also suggested by conceptual differences between the gift giving and investment forms of commitment behavior.

Gift giving can be construed as the most expressively based form of commitment behavior and investment behavior as the most instrumentally based. In our theory and related experiments, gifts involved little 
American Journal of Sociology

cost and could not be used instrumentally. They were simple, token gestures. Investment behavior entails the possibility of malfeasance, because the costs are significant if one invests but others do not. Being able to predict what the others will do is more important for investment than gift giving, simply because there is more at stake. It theoretically follows that trust would be crucial here. Thus, we suggest that actors who successfully exchange are prepared to engage in symbolic, expressive behavior toward others sooner than they are willing to take action involving substantial risk. The former requires positive feelings from interaction with the others and a sense of a cohesive group, while the latter requires sufficient trust. The dual process observed in our results highlights the importance of distinguishing instrumental and expressive kinds of commitment and adds conceptual support for the importance of trust for the former.

The fact that perceived predictability does not affect group cohesion also raises questions about the "boundary defining" role we attributed to uncertainty reduction and whether there are any conditions under which uncertainty reduction will have group formation effects. We argued that as the focal set of actors becomes more predictable, they are cognitively "set off" from others with whom an individual is less familiar. This ostensibly makes the focal group appear more "distinctive" and satisfies a condition known to facilitate group formation. We find no evidence for such an effect. However, our experimental procedures could have made it difficult for differences in predictability between the focal and alternative group to occur. When an agreement did not occur in the focal group, there was no uncertainty about whether an agreement with the alternative group would occur (i.e., it was automatic), and there was no negotiation process with the members of the alternative group (i.e., it was simulated). The distinctiveness effect may be most likely to occur when differences in the predictability of groups are substantial and salient. Under such conditions, we would expect uncertainty reduction to have group formation as well as trust effects. Future research should address this possibility.

\section{Exchange and Group Identity}

A fundamental point of our theorizing and research is to suggest that multiactor productive exchange has group formation effects. Broadly such effects can be cast in terms of commonalties between social exchange theory and a very different theoretical tradition, social identity theory. In social exchange theory (Molm and Cook 1995), interdependencies motivate exchanges, whereas in social identity theory and research (Tajfel and Turner 1986; Brewer 1993), interdependencies generate a sense of group- 
ness among actors. The latter is often termed "psychological group formation" (Rabbie and Horowitz 1988; Kramer 1991, 1993). Psychological group formation essentially involves individual commitments to the group (person-to-group attachments) that are manifest in collectively oriented behavior on behalf of the group and toward its members, for example, more favorable, cooperative, or generous behavior. Overall, social exchange theory emphasizes how interdependence leads to instrumental acts and behaviors, and social identity theory emphasizes how interdependence leads to symbolic or expressive behaviors. From exchange theory, "generous" behavior must be connected to an actor's self interest in some way, whereas from social identity theory, a rudimentary common group identity or affiliation is sufficient to produce such behavior toward other group members (see also Collins 1981, 1989).

This convergence between social exchange and social identity helps us to analyze how and when repeated exchange results in social units that are formed on a cognitive level. If social identity theories are correct, and there is much evidence to support their fundamental claims, then repetitive exchange in the context of interdependence should be a basis for the formation of relations and groups. Similar ideas can be found in Berger and Luckmann's (1967) analysis of "incipient institutionalization" and also in Collins's (1981) theory of interaction ritual chains. Berger and Luckmann argue that it often takes only one repetition of a behavior in interaction for the process of microinstitutionalization to begin; and for Collins (1981), recurrent interaction among the same actors is the microfoundation for macro order. Finally, Homans (1961) indicates that frequent interaction is sufficient to generate positive sentiment in relations and that this is especially likely when actors have alternative partners of less value than a focal relation or group, a condition met here and in most research on social exchange (Willer et al. 1997). Whether or not one fully subscribes to these particular theoretical viewpoints, there are strong theoretical reasons to believe that in the case of social exchange, mere frequency, repetition, or recurrence are powerful forces that contain the seeds of social order and related phenomena (e.g., group cohesion and commitment).

In a larger sense, the formation of a group from repeated exchange involves the transformation of what starts as a purely instrumental, selforiented relationship into a partly expressive, collectively oriented social unit. Relational cohesion theory (Lawler and Yoon 1993, 1996, 1998) stipulates that people will become more strongly committed to groups in which they experience positive feelings in interaction or exchange with others. Emotions are the linchpin between frequent exchange and group formation, and this is a key difference between our theory and social identity. The emotion is not produced by "groupness" per se, but 
American Journal of Sociology

by the interaction of its members; furthermore, under conditions typical of most exchanges (i.e., a joint task with joint responsibility for success or failure), people attribute their task-induced feelings in part to relevant social units (Weiner 1985). This makes the group salient as a positive social object and promotes a collective orientation to the exchange task. In this manner, the instrumental and the expressive are interwoven.

Our research can be construed as taking up the question of how interdependence generates social order in the form of group cohesion and commitment (Doreian and Fararo 1998; Durkheim 1933; Ekeh 1974; Hechter 1987). Whether it is a corporation undertaking a merger/ acquisition, an academic department staving off the recruitment of faculty by other institutions, or a rotary club whose members have simply lost interest, a fundamental problem is the commitment of members to the group. Our research suggests that certain kinds of social interactions contain basic ingredients to overcome the commitment problem. Specifically, when group members are interdependent on one another to produce a single product that benefits all, two interrelated processes work to promote instrumental and expressive forms of commitment. The first operates through uncertainty and trust; the second operates through positive emotion and relational cohesion. In the aforementioned examples, our theory helps explain why corporate profit sharing, joint research and teaching projects among faculty, and potluck dinners foster commitment to the larger group. In each case, the production of a single collective reward through joint activity triggers emotional and cognitive processes that yield cohesion and commitment.

In conclusion, this article shows how cohesion and commitment can develop in productive exchange contexts. The emotional/affective and uncertainty reduction effects of successful exchanges are crucial to this, and these are parallel processes that result in complementary kinds of commitment. Under favorable total and relative power dependence conditions, actors successfully negotiate repeated exchanges that unleash

dual processes resulting in commitment. Through an emotional/affective mechanism, they come to define themselves as a group, ascribe value to the group itself, and become more inclined to stay or continue with the group and to give members token gifts. Through an uncertainty reduction mechanism, they come to trust their exchange partners and become more willing to partake in a ventures that entail risk of malfeasance. Together, these dual processes provide a more general, multidimensional view of commitment and cohesion in networks and groups.

\section{APPENDIX}

The theory consists of two definitions and two axioms. Given each member's dependence on the group $(\mathrm{D} 1, \mathrm{D} 2, \mathrm{D} 3, \ldots, \mathrm{DN})$, the total dependence 
(TD) of $N$ members on the group is defined as the average of individual member's dependence (see also Molm 1987).

$$
\mathrm{TD}=\sum_{\mathrm{i}=1}^{N} \mathrm{Di} / N, \mathrm{TD}>0 .
$$

We define inequality of power dependence (DI) for the group as the average difference of individual dependencies on the focal group.

$$
\mathrm{DI}=\sum_{\mathrm{i}=1}^{N} \sum_{\mathrm{j}=1}^{N}|\mathrm{Di}-\mathrm{Dj}| / N \mathrm{C}_{2}, \mathrm{DI}>0,
$$

where $\mathrm{C}$ refers to a combination and $\mathrm{NC}_{2}$ is the total number of nonoverlapping pairs in a group of $N$ persons. DI approaches 0 when all members become equally dependent on the group.

In addition to these two concepts, the theory consists of two axioms. The first axiom stipulates the relation of total dependence and dependence inequality to structural cohesion in the group. The second axiom stipulates the endogenous process of the theory of relational cohesion (see Lawler and Yoon 1996).

$$
\begin{array}{r}
\text { AxIOM 1.-SC = SC (TD, DI, INT }) . \\
\mathrm{SC}_{\mathrm{TD}}>0, \\
\mathrm{SC}_{\mathrm{DI}}<0, \\
\mathrm{SC}_{\mathrm{INT}}<0,
\end{array}
$$

where $\mathrm{SC}_{\mathrm{TD}}$ refers to the first partial derivative of structural cohesion (SC) as a function of total dependence (TD), $\mathrm{SC}_{\mathrm{DI}}$ refers to the first partial derivative of structural cohesion (SC) as a function of dependence inequality (DI), and $\mathrm{SC}_{\mathrm{INT}}$ refers to the first partial derivative for the multiplicative effect of dependence inequality and total dependence.

Axiom 2.- $\mathrm{GC}=\mathrm{GC}(\mathrm{PE}, \mathrm{PR}) ; \mathrm{PR}=\mathrm{PR}(\mathrm{AF}) ; \mathrm{PE}=\mathrm{PE}(\mathrm{AF}) ; \mathrm{AF}$ $=\mathrm{AF}(\mathrm{SC})$.

$$
\begin{aligned}
& \mathrm{GC}_{\mathrm{PE}}>0, \\
& \mathrm{GC}_{\mathrm{PR}}>0, \\
& \mathrm{PR}_{\mathrm{AF}}>0,
\end{aligned}
$$


American Journal of Sociology

$$
\mathrm{PE}_{\mathrm{AF}}>0
$$

$$
\mathrm{AF}_{\mathrm{SC}}>0,
$$

where GC, PE, PR, and AF refer to group cohesion, positive emotion, predictability, and agreement frequency, respectively. The predictions (paths) shown in figure 3 are derived from axiom 2 by replacing equation (A8) in axiom 2 with equations (A1), (A2), and (A3) in axiom 1.

\section{REFERENCES}

Axelrod, Robert. 1984. The Evolution of Cooperation. New York: Basic Books.

Bacharach, Samuel B., and Edward J. Lawler. 1981. Bargaining: Power, Tactics, and Outcomes. San Francisco, Calif.: Jossey-Bass.

Berger, Peter L., and Thomas Luckmann. 1967. The Social Construction of Reality. New York: Doubleday.

Blau, Peter. 1964. Exchange and Power in Social Life. New York: John Wiley \& Sons.

$\rightarrow$ Bollen, Kenneth A., and Rick H. Hoyle. 1990. "Perceived Cohesion: A Conceptual and Empirical Examination." Social Forces 69:479-504.

$\rightarrow$ Brewer, Marilynn B. 1993. "Social Identity, Distinctiveness, and In-group Homogeneity." Social Cognition 11:150-64.

$\rightarrow$ Brines, Julie, and Kara Joyner. 1999. "The Ties That Bind: Principles of Cohesion in Cohabitation and Marriage." American Sociological Review 64:333-55.

$\rightarrow$ Collins, Randall. 1981. "On the Microfoundations of Macrosociology." American Journal of Sociology 86:984-1014.

$\rightarrow$. 1989. "Toward a Neo-Meadian Sociology of Mind." Symbolic Interaction 12: $1-32$.

Cook, Karen S., and Richard M. Emerson. 1984. "Exchange Networks and the Analysis of Complex Organizations." Pp. 1-30 in Research on the Sociology of Organizations, edited by Samuel B. Bacharach and Edward J. Lawler. Greenwich, Conn.: JAI Press.

$\rightarrow$ Cook, Karen S., Richard M. Emerson, Mary R. Gillmore, and Toshio Yamagishi. 1983. "The Distribution of Power in Exchange Networks: Theory and Experimental Evidence." American Journal of Sociology 89:275-305.

$\rightarrow$ Cook, Karen, and Joseph Whitmeyer. 1992. "Two Approaches to Social Structure: Exchange Theory and Network Analysis." Annual Review of Sociology 18:109-27.

Doreian, Patrick, and Tomas Fararo. 1998. The Problem of Solidarity: Theories and Models. Amsterdam: Gordon \& Breach.

Durkheim, Émile. 1915. The Elementary Forms of Religious Life. New York: Free Press.

- 1933. The Division of Labor in Society. New York: Free Press.

Ekeh, Peter. 1974. Social Exchange Theory. Cambridge, Mass.: Harvard University Press.

Emerson, Richard M. 1972. "Exchange Theory Part I: A Psychological Basis for Social Exchange.” Pp. 38-57 in Sociological Theories in Progress, vol. 2. Edited by J. Berger, M. Zelditch, Jr., and B. Anderson. Boston: Houghton-Mifflin.

$\rightarrow$ - 1976. "Social Exchange Theory." Annual Review of Sociology 2:335-62.

- 1981. "Social Exchange Theory." Pp. 30-65 in Social Psychology: Sociological Perspectives, edited by M. Rosenberg and R. H. Turner. New York: Basic Books.

Frank, Robert H. 1988. Passions within Reasons: The Strategic Role of Emotions. New York: W. W. Norton. 


\section{Productive Exchange}

$\rightarrow$ - 1993. "The Strategic Role of Emotions: Reconciling Over- and Undersocialized Accounts of Behavior." Rationality and Society 5 (2): 160-84.

Gillmore, Mary R. 1987. "Implications of General versus Restricted Exchange." Pp. 170-89 in Sociological Exchange Theory, edited by K. S. Cook. Newbury Park, Calif.: Sage.

$\rightarrow$ Granovetter, Mark. 1973. "The Strength of Weak Ties.” American Journal of Sociology 78:1360-80.

$\rightarrow-1985$. "Economic Action and Social Structure: The Problem of Embeddedness." American Journal of Sociology 91:481-510.

$\rightarrow$ Hall, John R. 1988. "Social Organization and Pathways of Commitment: Types of Communal Groups, Rational Choice Theory, and the Kanter Thesis." American Sociological Review 53:679-92.

$\rightarrow$ Hardin, G. 1968. "Tragedy of the Commons." Science 162:1243-48.

Heath, Anthony. 1975. Rational Choice and Social Exchange. Cambridge: Cambridge University Press.

Hechter, Michael. 1987. Principles of Group Solidarity. Berkeley: University of California Press.

Hochschild, Arlie R. 1983. The Managed Heart: Commercialization of Human Feeling. Berkeley: University of California Press.

$\rightarrow$ Hogg, A. Michael, and John C. Turner. 1985. "Interpersonal Attraction, Social Identification and Psychological Group Formation." European Journal of Social Psychology 15:51-66.

Homans, George L. 1961. Social Behavior: Its Elementary Forms. New York: Harcourt Brace Jovanovich.

Izard, Carroll E. 1977. Human Emotions. New York: Plenum Press.

Jöreskog, Karl G., and Dag Sörbom. 1993. Lisrel 8 User's Reference Guide. Chicago: Scientific Software International.

$\rightarrow$ Kahneman, Daniel, and Tversky, Amos. 1979. "On the Reality of Cognitive Illusions." Econometrica 47:263-91.

$\rightarrow$. 1996. "Judgment under Uncertainty: Heuristics and Biases." Psychological Review 103:582-91.

$\rightarrow$ Kanter, Rosabeth M. 1968. "Commitment and Social Organization: A Study of Commitment Mechanisms in Utopian Communities." American Sociological Review 33:499-517.

- 1972. Commitment and Community: Communes and Utopias in Sociological Perspective. Cambridge, Mass.: Harvard University Press.

Kemper, Theodore D. 1978. A Social Interactional Theory of Emotions. New York: Wiley.

$\rightarrow$ Kollock, Peter 1994. "The Emergence of Exchange Structures: An Experimental Study of Uncertainty, Commitment, and Trust." American Journal of Sociology 100:315-45.

Kramer, Roderick M. 1991. "Intergroup Relations and Organizational Dilemmas: The Role of Categorization Processes." Research in Organizational Behavior 13:191-228.

- 1993. "Cooperation and Organizational Identification." Pp. 110-33 in Social Psychology in Organizations: Advances in Theory and Research, edited by J. K. Murnighan. Englewood Cliffs, N.J.: Prentice Hall.

$\rightarrow$ Kramer, Roderick M., and Marilynn B. Brewer. 1984. "Effects of Group Identity on Resource Use in a Simulated Commons Dilemma." Journal of Personality and Social Psychology 46:1044-57.

Kramer, Roderick M., and Tom R. Tyler. 1996. Trust in Organizations: Frontiers of Theory and Research. Thousand Oaks, Calif.: Sage Publications.

$\rightarrow$ Lawler, Edward J. 1992a. "Choice Processes and Affective Attachments to Nested Groups: A Theoretical Analysis." American Sociological Review 57:327-39.

$\rightarrow$. 1992b. "Power Processes in Bargaining." Sociological Quarterly 33:17-34. 


\section{American Journal of Sociology}

$\rightarrow$ Lawler, Edward J., and Samuel B. Bacharach. 1987. "Comparison of Dependence and Punitive Forms of Power.” Social Forces 66:446-62.

$\rightarrow$ Lawler, Edward J., and Shane R. Thye. 1999. "Bringing Emotions into Social Exchange Theory." Annual Review of Sociology 25:217-44.

$\rightarrow$ Lawler, Edward J., and Jeongkoo Yoon. 1993. "Power and the Emergence of Commitment Behavior in Negotiated Exchange." American Sociological Review 58: 465-81.

$\rightarrow$. 1996. "Commitment in Exchange Relations: Test of a Theory of Relational Cohesion." American Sociological Review 61:89-108.

$\rightarrow$. 1998. "Network Structure and Emotion in Exchange Relations." American Sociological Review 63:871-94.

Lawler, Edward J., Jeongkoo Yoon, Mouraine R. Baker, and Michael D. Large. 1995. "Mutual Dependence and Gift Giving in Exchange Relations." Pp. 271-98 in Advances in Group Process, vol. 15. Edited by B. Markovsky, J. O'Brien, and K. Heimer. Greenwich, Conn.: JAI Press.

$\rightarrow$ Lincoln, James, and Arne Kalleberg. 1985. "Work Organization and Workforce Commitment: A Study of Plants and Employees in the U.S. and Japan.” American Sociological Review 50:738-60.

Lovaglia, Michael J. 1997. "Status, Emotion, and Structural Power." Pp. 159-78 in Status, Network, and Structure: Theory Development in Group Processes, edited by Jacek Szmatka, John Skvoretz, and Joseph Berger. Stanford, Calif.: Stanford University Press.

$\rightarrow$ Macy, Michael W. 1993. "Backward-Looking Social Control." American Sociological Review 58:819-36.

$\rightarrow$ Markovsky, Barry, David Willer, and Travis Patton. 1988. "Power Relations in Exchange Networks." American Sociological Review 53:220-36.

Molm, Linda. 1987. "Extending Power Dependence Theory: Power Processes and Negative Outcomes." Pp. 178-98 in Advances in Group Processes, edited by E. J. Lawler and B. Markovsky. Greenwich, Conn.: JAI Press.

$\rightarrow \longrightarrow$. 1990. "Structure, Action, and Outcomes: The Dynamics of Power in Social Exchange." American Sociological Review 55:427-47.

$\rightarrow \longrightarrow$. 1994. "Dependence and Risk: Transforming the Structure of Social Exchange." Social Psychology Quarterly 57:163-89.

Molm, Linda, and Karen Cook. 1995. "Social Exchange and Exchange Networks." Pp. 209-35 in Sociological Perspectives on Social Psychology, edited by K. Cook, G. Fine, and J. House. Boston: Allyn and Bacon.

Parsons, Talcott. 1951. The Social System. New York: Free Press.

$\rightarrow$ Patton, Travis, and David Willer. 1990. "Connection and Power in Centralized Exchange Networks." Journal of Mathematical Sociology 16:31-49.

$\rightarrow$ Platt, I. 1973. "Social Traps." American Psychologist 28:641-51.

$\rightarrow$ Pruitt, Dean J., and M. J. Kimmel. 1977. "Twenty Years of Experimental Gaming: Critique, Synthesis and Suggestions for the Future." Annual Review of Psychology 28:363-92.

Rabbie, Jacob M., and Murray Horowitz. 1988. "Category versus Groups as Explanatory Concepts in Intergroup Relations." European Journal of Social Psychology 19:172-202.

Rapoport, Anatol, and Albert M. Chammah. 1965. Prisoner's Dilemma: A Study in Conflict and Cooperation. Ann Arbor: University of Michigan Press.

$\rightarrow$ Russell, James A. 1980. "A Circumplex Model of Affect." Journal of Personality and Social Psychology 39 (6): 1161-78.

Schelling, Thomas C. 1960. The Strategy of Confict. Cambridge: Harvard University Press.

Simmel, Georg. 1950. The Sociology of Georg Simmel. Glencoe, Ill.: Free Press.

$\rightarrow$ Skvoretz, John, and Michael J. Lovaglia. 1995. "Who Exchanges with Whom: 


\section{Productive Exchange}

Structural Determinants of Exchange Frequency in Negotiated Exchange Networks." Social Psychology Quarterly 58:163-77.

Tajfel, Henri, and John C. Turner. 1979. "An Integrative Theory of Intergroup Conflict.” Pp. 33-47 in The Social Psychology of Intergroup Relations, edited by W. G. Austin and S. Worchel. Monterey, Calif.: Brooks/Cole.

. 1986. "The Social Identity Theory of Intergroup Behavior." Pp. 7-24 in Psychology of Intergroup Relations, edited by S. Worchel and W. G. Austin. Chicago: Nelson-Hall.

Thibaut, John W., and Harold H. Kelley. 1959. The Social Psychology of Groups. New York: John Wiley \& Sons.

$\rightarrow$ Thye, Shane R. 2000. "Reliability in Experimental Sociology." Social Forces 74: 1277-309.

$\rightarrow$ Tversky, Amos, and Kahneman, Daniel. 1974. "Prospect Theory: An Analysis of Decision under Risk." Science 185:1124-31.

$\rightarrow-$ 1981. "The Framing of Decisions and the Psychology of Choice." Science 211: 453-58.

Tyler, Tom R. 1990. Why People Obey the Law: Procedural Justice, Legitimacy, and Compliance. New Haven, Conn.: Yale University Press.

$\rightarrow \longrightarrow$. 1994. "Psychological Models of the Justice Motive: Antecedents of Distributive and Procedural Justice." Journal of Personality and Social Psychology 67:850-63.

$\rightarrow$ Weiner, Bernard. 1985. "An Attributional Theory of Achievement Motivation and Emotion." Psychological Review 92:548-73.

Willer, David, ed. 1999. Network Exchange Theory. Westport, Conn.: Praeger Publishers.

$\rightarrow$ Willer, David, Michael J. Lovaglia, and Barry Markovsky. 1997. "Power and Influence: A Theoretical Bridge." Social Forces 76 (2): 571-603.

$\rightarrow$ Williamson, Oliver E. 1981. "The Economics of Organization: The Transaction Cost Approach." American Journal of Sociology 87:549-77.

Yamagishi, Toshio. 1995. "Social Dilemmas." Pp. 311-34 in Sociological Perspectives on Social Psychology, edited by K. Cook, G. Fine, and J. House. Boston: Allyn \& Bacon.

$\rightarrow$ Yamagishi, Toshio, and Karen Cook. 1993. "Generalized Exchange and Social Dilemmas." Social Psychology Quarterly 56:253-48. 